\section{$\underset{\substack{\text { hommes } \\ \text { \& migrations }}}{ }$}

\section{Hommes \& migrations}

Revue française de référence sur les dynamiques

migratoires

$1301 \mid 2013$

Migrations et mondes ruraux

\title{
La Cité Rose
}

Film de Julien Abraham

\section{Eugénie Barbezat}

\section{Q OpenEdition \\ 12 Journals}

\section{Édition électronique}

URL : http://journals.openedition.org/hommesmigrations/1961

DOI : 10.4000/hommesmigrations. 1961

ISSN : 2262-3353

\section{Éditeur}

Musée national de l'histoire de l'immigration

\section{Édition imprimée}

Date de publication : 1 janvier 2013

Pagination : 206-207

ISBN : 978-2-919040-21-6

ISSN : $1142-852 X$

\section{Référence électronique}

Eugénie Barbezat, « La Cité Rose », Hommes \& migrations [En ligne], 1301 | 2013, mis en ligne le 29 mai 2013, consulté le 22 septembre 2020. URL : http://journals.openedition.org/hommesmigrations/1961 ; DOI : https://doi.org/10.4000/hommesmigrations. 1961

Ce document a été généré automatiquement le 22 septembre 2020.

Tous droits réservés 


\section{La Cité Rose}

Film de Julien Abraham

\section{Eugénie Barbezat}

1 Aucun nom d'acteur vedette au générique de ce premier long-métrage réalisé par Julien Abraham, une thématique qui, en général, résiste plutôt mal aux clichés, une affiche aux couleurs vives sur laquelle trois gamins semblent rejouer Jackass et cette phrase : "Il ne faut jamais s'arrêter de rêver" juste au-dessus du titre, en lettres rouges, énormes, La Cité ROSE... Autant d'éléments qui font de ce film un véritable objet cinématographique non classifiable! Va-t-on assister à une vision de la banlieue, à la manière de Bienvenue chez les Chtis? À un documentaire plein de bons sentiments mettant en scène des jeunes des cités?

2 Dès les premiers plans du film, toutes ces appréhensions s'évaporent. Pas de doutes, on est bien au cinéma : la musique, les mouvements de caméra, les plans panoramiques en surplomb de la cité, l'enchaînement des séquences et surtout l'incroyable travail sur la photo et la lumière nous indiquent que ce premier film est ambitieux. Julien Abraham et toute son équipe y ont mis toute leur énergie et leur talent et on va en prendre plein la vue! Aussi, ils ont fait des choix courageux. Tout d'abord, en dévoilant, dès les premières secondes, l'épilogue, tragique, de l'histoire. Ainsi, le film tient non pas grâce à un suspens savamment entretenu, mais par la force du scénario qui met en scène les parcours de trois cousins: Mitraillette, douze ans, par la voix duquel l'histoire est racontée, Isma, son cousin de seize ans, qui se laisse séduire par Narcisse, le caïd du quartier et devient guetteur pour la bande de dealers de la cité, et son grand frère, Djibril, vingt-deux ans, brillant étudiant en droit à La Sorbonne, futur avocat, amoureux d'une fille de bonne famille de sa promo qu'il n'ose pas présenter à sa famille, tandis que Mitraillette, lui, aimerait sortir avec Océane, la plus belle fille du collège... Leurs destins sont liés, au cœur des tours de La Cité Rose, un endroit qui existe vraiment, à Pierrefitte en Seine-Saint-Denis. D'ailleurs c'est de cette banlieue que sont originaires deux des coscénaristes et c'est là que vivent certains acteurs, des amateurs recrutés sur place pour incarner les personnages du film.

3 Ensuite, dans une volonté affichée de ne pas éluder les phénomènes de gangs, de trafic de drogues et de violence, en plus de montrer les poursuites avec la police, les 
règlements de comptes entre dealer et les scènes d'initiation assez insoutenables, le film offre l'opportunité, rare, d'entendre les arguments de ceux qui se livre à ces trafics. Il y est aussi question de la possibilité de faire de brillantes études lorsque l'on est issu de l'immigration et à fortiori d'une zone plutôt "excentrée"... et de la difficulté d'intégrer la vie professionnelle quand on n'a pas les bonnes cartes au départ....

4 Sans pathos mais avec humour et tendresse, ce film dresse une galerie de portraits d'adolescents et préadolescents plus attachants les uns que les autres. On suit leurs histoires d'amour et d'amitié, leurs bagarres et leurs jeux, leurs concours et leurs paris débiles... Et leur bonheur de vivre ici, ensemble dans cette cité-village où tout le monde se connaît. Au détour d'une conversation entre les femmes du quartier, on comprend que les préjugés raciaux sont monnaie courante, même chez ceux qui, par ailleurs, les subissent. À chaque fois que l'une des thématiques relatives à l'image de la banlieue et de ceux, souvent issus de l'immigration, qui y habitent est abordée, c'est au travers de scènes très nuancées. Sans parti pris. En cela Julien Abraham réussit la gageure de nous faire réfléchir sans devenir "donneur de leçons".

5 Au-delà du scénario, c'est aussi le casting qui fait de La Cité Rose, tourné au cœur du quartier à l'été 2011, un film qui sonne juste. Le réalisateur a fait le choix de recruter sur place la plupart des comédiens et leur a laissé une part d'improvisation. Les acteurs sont donc pour la plupart des novices qui, avec leur langage, leur gestuelle et aussi leurs maladresses, apportent des accents de vérité et de sincérité indéniables. D'ailleurs, presque tous ont été repérés à l'issue des premières projections et certains comme Azize Diabaté Abdoulaye, qui incarne magnifiquement Mitraillette, sont sans doute promis à une brillante carrière.

6 À moins qu'on ne les revoie bientôt à l'écran dans leurs propres rôles. En effet, au départ, Julien Abraham, inspiré par La Cité des hommes, une série brésilienne qui raconte le quotidien, fait de hauts et de bas, de deux jeunes des favelas de Rio, voulait faire une série. Finalement, La Cité Rose est devenu un long-métrage mais la structure du scénario qui laisse beaucoup d'ouvertures possibles et le foisonnement des personnages, tous plus truculents les uns que les autres, n'excluent pas une suite... La poursuite de cette belle aventure dépend assurément de l'accueil réservé au film par le public, donc courrez le voir en famille et parlez-en entre et autour de vous ! 